Received: November 3, 2008

Accepted after revision: December 31, 2008

Published online: August 6, 2009

\title{
Growth-Dependent Changes in the Contribution of Carbon Monoxide to Arteriolar Function
}

\author{
Julie Balch Samora Adam G. Goodwill Jefferson C. Frisbee \\ Matthew A. Boegehold \\ Department of Physiology and Pharmacology, and Center for Interdisciplinary Research in Cardiovascular \\ Sciences, West Virginia University School of Medicine, Morgantown, W. Va., USA
}

\section{Key Words}

Microcirculation $\cdot$ Endothelium $\cdot$ Postnatal growth $\cdot$ Carbon monoxide

\begin{abstract}
Background/Aims: Endothelium-dependent dilation of skeletal muscle arterioles is mediated by unknown factors in very young rats. We assessed the possible contribution of carbon monoxide (CO) to this dilation and to dilation in older animals. Methods: The effects of de-endothelialization or various pharmacological inhibitors on responses to $\mathrm{CO}$ or endothelium-dependent dilators were studied in gracilis muscle arterioles from rats at 3-4 weeks ('weanlings') and 6-7 weeks ('juveniles'). Results: Exogenous CO constricted, rather than dilated, arterioles from both age groups. This constriction was reduced by endothelial removal or NOS inhibition in juvenile, but not weanling, arterioles. In contrast, this constriction was abolished by $\mathrm{K}^{+}$channel inhibition in weanling, but not juvenile, arterioles. The heme precursor $\delta$-aminolevulinic acid constricted juvenile arterioles but did not affect weanling arterioles. The heme oxygenase inhibitor chromium (III) mesoporphyrin IX abolished the endothelium-dependent dilation of juvenile arterioles to simvastatin, and reduced ACh- and simvastatin-induced dilations of
\end{abstract}

weanling arterioles. Conclusion: These findings suggest that relatively high concentrations of exogenous $\mathrm{CO}$ can cause constriction by inhibiting endothelium-derived $\mathrm{NO}$ in juvenile arterioles and inhibiting $\mathrm{K}^{+}$channels in weanling arterioles. Endogenous $\mathrm{CO}$ produced at lower concentrations can contribute to endothelium-dependent dilation in both age groups.

Copyright $\odot 2009$ S. Karger AG, Basel

\section{Introduction}

Studies from our laboratory have documented that postnatal growth of the microvasculature is accompanied by progressive changes in a number of factors that can influence arteriolar tone and blood flow [1-4]. For example, skeletal muscle arterioles from young rats exhibit fully developed endothelium-dependent dilation, but these responses are not mediated by nitric oxide (NO), cyclooxygenase metabolites or hydrogen peroxide $\left(\mathrm{H}_{2} \mathrm{O}_{2}\right)$, as they are in arterioles from more mature rats $[1,2]$. The chemical mediator(s) of arteriolar endothelium-dependent dilation in these younger animals have not yet been identified.

\section{KARGER}

두 2009 S. Karger AG, Basel

Fax +4161306 1234 E-Mail karger@karger.ch www.karger.com www.karger.com/jvr
Dr. Matthew A. Boegehold

Center for Interdisciplinary Research in Cardiovascular Sciences

Robert C. Byrd Health Sciences Center, West Virginia University School of Medicine PO Box 9105, Morgantown, WV 26505-9105 (USA)

Tel. +1 304293 5240, Fax +1 304293 5513, E-Mail mboegehold@hsc.wvu.edu 
Carbon monoxide (CO), a signaling molecule that can be important for regulation of vascular tone and blood flow under some conditions [5-7], is produced via metabolism of heme by heme oxygenase (HO), with biliverdin and free iron also being generated in the process [8]. The 2 isoforms of this enzyme, HO-1 and HO-2, have been found in endothelial $[9,10]$ and vascular smooth muscle $[11,12]$ cells. HO-1 is an inducible isoform; its expression can be dramatically increased by numerous stimuli including hypoxia, hypertension, endotoxic shock and shear stress [12-14]. In contrast, HO-2 is constitutive and therefore presumably responsible for moment-tomoment changes in vascular $\mathrm{CO}$ production in the absence of pathologic stimuli [15]. CO is generally considered to be a vasodilator molecule [16]; among other vessel types, it has been found to relax rabbit and rat aorta [17, 18], dog coronary arteries [17], rabbit pulmonary arteries [19], rat afferent arterioles [20] and pial arterioles in newborn pigs [21]. However, $\mathrm{CO}$ can also reduce NO production by inhibiting NO synthase (NOS) [22, 23], and at least 1 study has demonstrated that $\mathrm{CO}$ can induce arteriolar constriction [24]. The effect of $\mathrm{CO}$ on arteriolar tone in skeletal muscle is variable. Some investigators have found $\mathrm{CO}$-dependent dilation of gracilis muscle arterioles [25], whereas others have found that both exogenously applied and endogenously formed CO constricts these arterioles after pretreatment with phenylephrine [24]. Such discrepancies may be due in part to differences in the concentration of $\mathrm{CO}$ reached at or within the vessel wall. For example, NO release in rat afferent arterioles is increased at low CO levels but suppressed at high CO levels [20].

Because $\mathrm{CO}$ has been identified as an important vasoactive factor in the cerebral microcirculation of newborn pigs [21], we undertook the current study to determine if $\mathrm{CO}$ could be playing a similar role as a mediator of endothelium-dependent dilation in skeletal muscle arterioles of young rats. A second aim of this study was to determine if there is a change in the mechanism(s) by which $\mathrm{CO}$ can influence arteriolar tone during rapid juvenile growth.

\section{Materials and Methods}

\section{Animals}

All surgical and experimental procedures were approved by the West Virginia University Animal Care and Use Committee. Experiments were performed on isolated gracilis muscle arterioles from male Sprague-Dawley rats (Harlan Sprague Dawley, Indianapolis, Ind., USA) of 3 age groups: 3-4 weeks ('weanlings'),
6-7 weeks ('juveniles') and 9-10 weeks ('adults'). Arterioles from adult rats were used in only 1 subset of the experiments described below (see Results).

Rats were anesthetized by intraperitoneal injection of sodium pentobarbital (50 $\mathrm{mg} / \mathrm{kg}$ body weight), with supplemental anesthetic ( $10 \%$ of original dose) administered if needed. The right carotid artery was cannulated with polyethylene tubing for measurement of mean arterial pressure, which was assessed immediately before removal of the gracilis arteriole.

Preparation of Isolated Vessels

The small muscular branch of the femoral artery that directly supplies the gracilis muscle (a first-order arteriole) was removed, handling only the surrounding connective tissue to minimize vessel stretching or damage. The rat was sacrificed immediately after vessel removal by intracardiac injection of sodium pentobarbital. The excised vessel was placed in warmed physiological salt solution (PSS) equilibrated with $21 \% \mathrm{O}_{2}, 5 \% \mathrm{CO}_{2}$ and $74 \% \mathrm{~N}_{2}$, and having the following composition (in $\mathrm{mM}$ ): $119 \mathrm{NaCl}, 4.7 \mathrm{KCl}$, $1.17 \mathrm{MgSO}_{4}, 1.6 \mathrm{CaCl}_{2}, 1.18 \mathrm{NaH}_{2} \mathrm{PO}_{4}, 24 \mathrm{NaHCO}_{3}, 0.026$ EDTA and 5.5 glucose. After isolation, each vessel was prepared for in vitro video microscopy as previously described [26]. Briefly, the vessel was mounted in a heated $\left(37^{\circ} \mathrm{C}\right)$ chamber that allowed for its lumen and exterior surface to be perfused and superfused, respectively, with PSS from separate reservoirs. The vessel was cannulated at both ends with glass micropipettes (tip diameters: 50 $\mu \mathrm{m}$ for weanling vessels, $70 \mu \mathrm{m}$ for juvenile and adult vessels) and secured to the inflow and outflow pipettes using 9-0 nylon suture. Any side branches were ligated with a single strand teased from 6-0 silk suture. The inflow pipette was connected to a reservoir perfusion system for control of intralumenal pressure and flow. The vessel was then extended to its in situ length and equilibrated at $80 \%$ of the animal's mean arterial pressure to approximate its normal in vivo perfusion pressure [27].

Vessel diameter was measured using an onscreen video micrometer. Any vessel that did not demonstrate endothelial viability, as judged by pronounced dilation to $10^{-7} \mathrm{M}$ acetylcholine (ACh; Sigma Chemical, St. Louis, Mo., USA), was not used in this study. Changes in vessel diameter to all agonists and inhibitors (see below) were made under static, zero-flow conditions after a 30-min equilibration period with continuous perfusion. Resting vascular tone under zero-flow conditions was calculated as $\left(\Delta \mathrm{D} / \mathrm{D}_{\max }\right) \times 100$, where $\Delta \mathrm{D}$ is the diameter increase from rest in response to $\mathrm{Ca}^{2+}$-free PSS (30- to 40-min equilibration with $\mathrm{Ca}^{2+}$-free bath solution), and $\mathrm{D}_{\max }$ is the maximum diameter measured under these conditions.

Agonists

Endothelium-dependent dilation was elicited by application of ACh or simvastatin (Merck Research Laboratories, Rahway, N.J., USA) at bath concentrations of $10^{-5}$ or $10^{-7}$ M [3, 4]. Simvastatin was first activated by alkaline lysis $(5.25 \mathrm{ml}$ of $0.1 \mathrm{~N} \mathrm{NaOH}$ per $140 \mathrm{mg}$, dissolved in $3.5 \mathrm{ml}$ of ETOH) at $50^{\circ} \mathrm{C}$ for $2 \mathrm{~h}$. The resulting solution was then diluted to a volume of $35 \mathrm{ml}$ with PBS, and neutralized to $\mathrm{pH} 7.4$ with $\mathrm{HCl}$. One-milliliter aliquots of this solution were then serially diluted with PBS for addition to the vessel bath.

CO-saturated solution (CP grade 99.5\%; Airgas Mid America, Bowling Green, Ky., USA) was prepared as described by Johnson and Johnson [24]. Briefly, ice-cold distilled $\mathrm{H}_{2} \mathrm{O}$ was vigorously 
bubbled with $\mathrm{CO}$ through a glass gas diffuser for $30 \mathrm{~min}$ to prepare a $10^{-2} \mathrm{M}$ solution. Increasing volumes of this solution were incrementally added to the vessel bath to produce final CO concentrations of $10^{-6}, 10^{-5}$ or $10^{-4} \mathrm{M}$. After each application, the vessel was allowed to return to its control diameter before the next $\mathrm{CO}$ application. Control experiments were performed using icecold $\mathrm{H}_{2} \mathrm{O}$ bubbled with $\mathrm{N}_{2}$ (Airgas Mid America). To stimulate endogenous $\mathrm{CO}$ production through $\mathrm{HO}$ activity, the heme precursor $\delta$-aminolevulinic acid ( $\delta$-ALA; Frontier Scientific, Logan, Utah, USA) was added to the bath at a concentration of $10^{-6} \mathrm{M}$ [28].

\section{Inhibitors}

Some vessels were pretreated with chromium (III) mesoporphyrin IX chloride (CrMP; Frontier Scientific), a competitive inhibitor of HO that is less sensitive to photo degradation than other metalloporphyrins [29]. Although there are many commercially made metalloporphyrins that inhibit HO, CrMP was chosen because it is the most selective inhibitor of $\mathrm{HO}$ activity [30]. A $10^{-2} \mathrm{M}$ stock solution of CrMP in $0.1 \mathrm{~N} \mathrm{NaOH}$ was diluted in the bath to produce a final concentration of $10^{-5} \mathrm{M}$ [28]. During exogenous $\mathrm{CO}$ application, endogenous $\mathrm{CO}$ production was also inhibited with CrMP to more directly assess intrinsic vascular responsiveness to $\mathrm{CO}$.

To evaluate possible interactions of exogenous or endogenous $\mathrm{CO}$ with the NO system, the NOS inhibitor $\mathrm{N} \omega$-nitro-L-arginine methyl ester (L-NAME; Sigma) was added to the bath at a concentration of $10^{-4} \mathrm{M}$ [31], alone or in the presence of CrMP. Both CrMP and L-NAME were administered for $20 \mathrm{~min}$ before vessels were challenged with agonists.

The contribution of potassium $\left(\mathrm{K}^{+}\right)$channels to arteriolar responses was assessed by using iberiotoxin (Ibtx; Sigma) [32], and the antidiabetic sulphonylurea, glibenclamide (Glib; Sigma) [33]. We used a $10^{-7}-\mathrm{M}$ bath concentration of Ibtx to selectively block $\mathrm{Ca}^{2+}$-activated $\mathrm{K}^{+}\left(\mathrm{K}_{\mathrm{Ca}}\right)$ channels $[31,32]$, and $10^{-6} \mathrm{M}$ Glib to selectively block ATP-sensitive $\mathrm{K}^{+}\left(\mathrm{K}_{\mathrm{ATP}}\right)$ channels [34].

\section{Endothelial Denudation}

To determine the role of the endothelium in mediating arteriolar responses to exogenous $\mathrm{CO}$, the endothelium was removed in some experiments by mechanical abrasion [35]. The pipette tip at each end of the vessel was gently advanced and then retracted through the vessel lumen 3 times to ensure elimination of the endothelium. We have previously verified that this method successfully denudes the endothelium of gracilis muscle arterioles without affecting the underlying smooth muscle [1]. To verify that smooth muscle function was intact following denudation in the current experiments, vasoconstrictor responses to $10^{-5} \mathrm{M}$ phenylephrine (Sigma) and vasodilator responses to $10^{-5} \mathrm{M}$ sodium nitroprusside (SNP; Sigma) were assessed before and after the denudation procedure. Only those vessels with unchanged responses to both agonists were included in the final data set.

\section{HO-1 and HO-2 Protein Measurements}

Gracilis artery/arteriole segments were harvested from weanling and juvenile rats, snap frozen in liquid $\mathrm{N}_{2}$, and stored at $-80^{\circ} \mathrm{C}$ until analysis. Protein was harvested from vessels by repeated vortexing and boiling in a sample buffer containing 0.225 $\mathrm{M}$ Tris- $\mathrm{Cl}$ pH 6.8, 50\% glycerol, $5 \%$ SDS, $0.25 \mathrm{M}$ dithiothreitol and $5 \% 2$-mercaptoethanol. Total protein concentration of each sam- ple was determined using a Nano-Orange assay (Invitrogen, Carlsbad, Calif., USA) according to the manufacturer's protocol. For each gel, protein samples were diluted in sample buffer to an equal concentration, boiled for $10 \mathrm{~min}$ and spun for $10 \mathrm{~min}$ at $9,300 \mathrm{~g}$ prior to loading onto precast $10 \%$ Bis-Tris polyacrylamide gels (Invitrogen). Gels were loaded with $50 \mu \mathrm{g}$ total protein per well. Electrophoresis was carried out at $150 \mathrm{~V}$ for $1.5 \mathrm{~h}$ and resolved proteins were transferred to an Immobilon PVDF membrane (Millipore, Billerica, Mass., USA) at $30 \mathrm{~V}$ for $1.25 \mathrm{~h}$ using Invitrogen's Sure Lock Mini-Cell electrophoresis system and associated X-Cell II Blot Module. Membranes were blocked overnight at $4^{\circ} \mathrm{C}$ in Superblock T-20 (Pierce Biotechnology, Rockford, Ill., USA) and then incubated with either HO-1 or HO-2 antibodies (Assay Designs; Stressgen, Ann Arbor, Mich., USA) for $1.5 \mathrm{~h}$. Membranes were then washed and incubated with appropriate horseradish peroxidase-conjugated secondary antibody. To verify equal protein loading among lanes, membranes were washed and incubated with antibody to glyceraldehyde 3-phosphate dehydrogenase (GAPDH; Fitzgerald Industries International Inc., Concord, Mass., USA) for $1 \mathrm{~h}$, washed, and incubated with appropriate secondary antibody. All proteins were visualized using an Amersham ECL Western blotting kit.

\section{Data and Statistical Analysis}

For each arteriole, vascular tone at each pressure was calculated as follows: tone $=\left[\left(D_{\max }-D_{\text {rest }}\right) / D_{\max }\right] \times 100$, where $D_{\max }$ is the passive diameter and $\mathrm{D}_{\text {rest }}$ is the resting diameter. A tone of $100 \%$ would represent complete vessel closure, whereas $0 \%$ would represent a completely passive vessel. All data are presented as mean \pm SE. For all analyses, a probability value of $\mathrm{p}<0.05$ was considered to be statistically significant. Dilation in response to $\mathrm{Ca}^{2+}$-free PSS is expressed as percent increase from control diameter. Differences among the means of individual experimental groups were evaluated by one- or two-way ANOVA (post hoc analysis: Newman-Keuls test), or by an unpaired Student's t test when 2 independent means were compared.

\section{Results}

General characteristics of all rats from which vessels were removed for in vitro study are reported in table 1. Most experiments were conducted on vessels from weanling and juvenile rats only, although the effects of CrMP on responses to $\mathrm{ACh}$ and simvastatin were also assessed in arterioles from adult rats (see below). Body weight increased with age from weanlings to adults, but mean arterial pressure increased only from weanling to juvenile rats, with no further increase from juvenile to adult rats. Table 1 also summarizes the general characteristics of all arterioles used in this study. Resting and passive arteriolar diameters progressively increased with age, but the level of spontaneous tone that developed upon vessel pressurization progressively decreased with age.

CrMP had no effect on resting arteriolar diameters in any age group (table 2 ). $\delta$-ALA significantly reduced the 
Table 1. General characteristics of all rats and vessels used for functional studies

\begin{tabular}{lccc}
\hline & Weanlings & Juveniles & Adults \\
\hline Animal characteristics & & & \\
$\mathrm{n}$ & 47 & 52 & 6 \\
Age, days & $25.3 \pm 0.3$ & $43.8 \pm 0.5^{*}$ & $64.5 \pm 0.7^{* *}$ \\
Body weight, g & $62 \pm 1$ & $168 \pm 2^{*}$ & $294 \pm 7^{* *}$ \\
MAP, mm Hg & $76 \pm 1$ & $97 \pm 2^{*}$ & $98 \pm 5^{*}$ \\
\hline Vessel characteristics & & & \\
$\mathrm{n}$ & 47 & 52 & 6 \\
Resting diameter, $\mu \mathrm{m}$ & $34 \pm 1$ & $51 \pm 2^{*}$ & $77 \pm 5^{* *}$ \\
Passive diameter, $\mu \mathrm{m}$ & $57 \pm 1$ & $79 \pm 2^{*}$ & $109 \pm 6^{* *}$ \\
Resting vascular tone & $41 \pm 2$ & $35 \pm 2^{*}$ & $29 \pm 2^{* *}$ \\
\multicolumn{1}{c}{$\%$ max. } & & & \\
\hline
\end{tabular}

Values are given as means \pm SE. MAP $=$ Mean arterial pressure. ${ }^{*} \mathrm{p}<0.05$ vs. weanling group; ${ }^{* *} \mathrm{p}<0.05$ vs. weanling and juvenile groups.

Table 2. Summary of resting arteriolar diameters under control conditions and after treatment with CrMP $\left(10^{-5} \mathrm{M}\right)$ or $\delta$-ALA $\left(10^{-6} \mathrm{M}\right)$

\begin{tabular}{lrccccc}
\hline & $\mathrm{n}$ & Control & CrMP & $\mathrm{n}$ & Control & $\delta$-ALA \\
\hline Adults & 6 & $77 \pm 5$ & $78 \pm 3$ & - & - & - \\
Juveniles & 16 & $47 \pm 3$ & $47 \pm 3$ & 10 & $52 \pm 3$ & $39 \pm 6^{*}$ \\
Weanlings & 17 & $32 \pm 2$ & $37 \pm 3$ & 7 & $35 \pm 3$ & $38 \pm 4$ \\
\hline
\end{tabular}

Values are given as means \pm SE. ${ }^{*} \mathrm{p}<0.05$ vs. control.

resting diameter of juvenile arterioles (by $25 \pm 1 \%$ ), but not weanling arterioles. Exogenous CO caused significant arteriolar constriction in both groups, with weanling arterioles constricting significantly more than juvenile arterioles in response to $10^{-6}$ and $10^{-5} \mathrm{M} \mathrm{CO}$ (fig. 1). The $\mathrm{CO}$ vehicle alone (equilibrated with $\mathrm{N}_{2}$ ) had no effect in either group (data not shown). CrMP was without effect on these responses to exogenous $\mathrm{CO}$ in either group, indicating that there were no acute changes in endogenous $\mathrm{CO}$ production that could influence arteriolar behavior under these conditions (data not shown).

L-NAME treatment reduced the resting diameter of both juvenile arterioles (from $55 \pm 5$ to $40 \pm 5 \mu \mathrm{m}$, a $27 \%$ average diameter reduction) and weanling arterioles (from $35 \pm 4$ to $25 \pm 3 \mu \mathrm{m}$, a $29 \%$ average diameter reduction). In contrast, L-NAME had no effect on resting diameters in either group if CrMP was present $(44 \pm 6$ before vs. 44

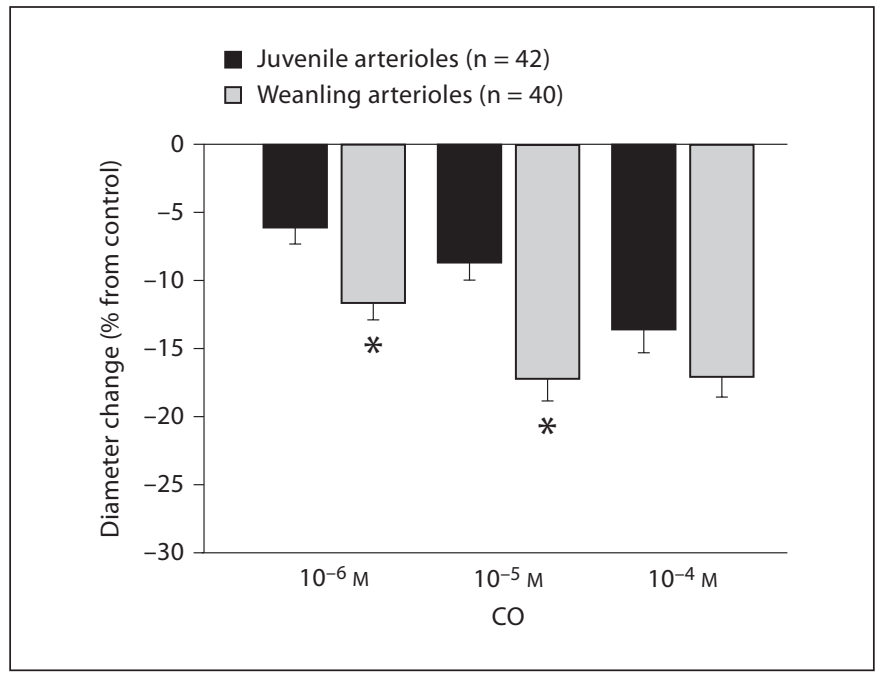

Fig. 1. Responses of gracilis muscle arterioles from juvenile and weanling rats to increasing concentrations of exogenous $\mathrm{CO}$. Values are given as means $\pm \mathrm{SE} .{ }^{*} \mathrm{p}<0.05$ vs. juvenile response.

$\pm 4 \mu \mathrm{m}$ after L-NAME in juveniles, $30 \pm 3$ before vs. 37 $\pm 4 \mu \mathrm{m}$ after L-NAME in weanlings). However, L-NAME abolished the constrictor responses of juvenile arterioles to exogenous $\mathrm{CO}$ whether or not CrMP was present (fig. 2a, b). L-NAME had no effect on weanling arteriole responses to $\mathrm{CO}$ at any concentration (fig. 3a), although it tended to reduce these responses to $\mathrm{CO}$ in the presence of CrMP (significantly at $10^{-6} \mathrm{M} \mathrm{CO}$ ) (fig. 3b).

Treatment with Ibtx + Glib reduced the resting diameters of both juvenile arterioles (from $51 \pm 6$ to $35 \pm$ $4 \mu \mathrm{m}$, a $31 \%$ average diameter reduction) and weanling arterioles (from $43 \pm 2$ to $29 \pm 3 \mu \mathrm{m}$, a $33 \%$ average diameter reduction). For juvenile arterioles, Ibtx + Glib had no effect on CO-induced constriction, whether or not CrMP was present (fig. 2c, d). However, for weanling arterioles, Ibtx + Glib abolished the constrictor responses to exogenous $\mathrm{CO}$ at all concentrations, whether or not CrMP was present (fig. 3c, d).

Endothelial removal completely abolished responses to $10^{-5} \mathrm{M}$ ACh in both juvenile and weanling arterioles (data not shown). After the denudation procedure, resting diameters tended to be smaller in juvenile arterioles (55 \pm 2 before vs. $49 \pm 2 \mu \mathrm{m}$ after denudation) and weanling arterioles ( $26 \pm 3$ vs. $20 \pm 2 \mu \mathrm{m}$ ), but these diameter reductions did not reach statistical significance. Endothelial removal had no effect on CO-induced constriction of weanling arterioles, but significantly reduced these responses in juvenile arterioles (fig. 4). 


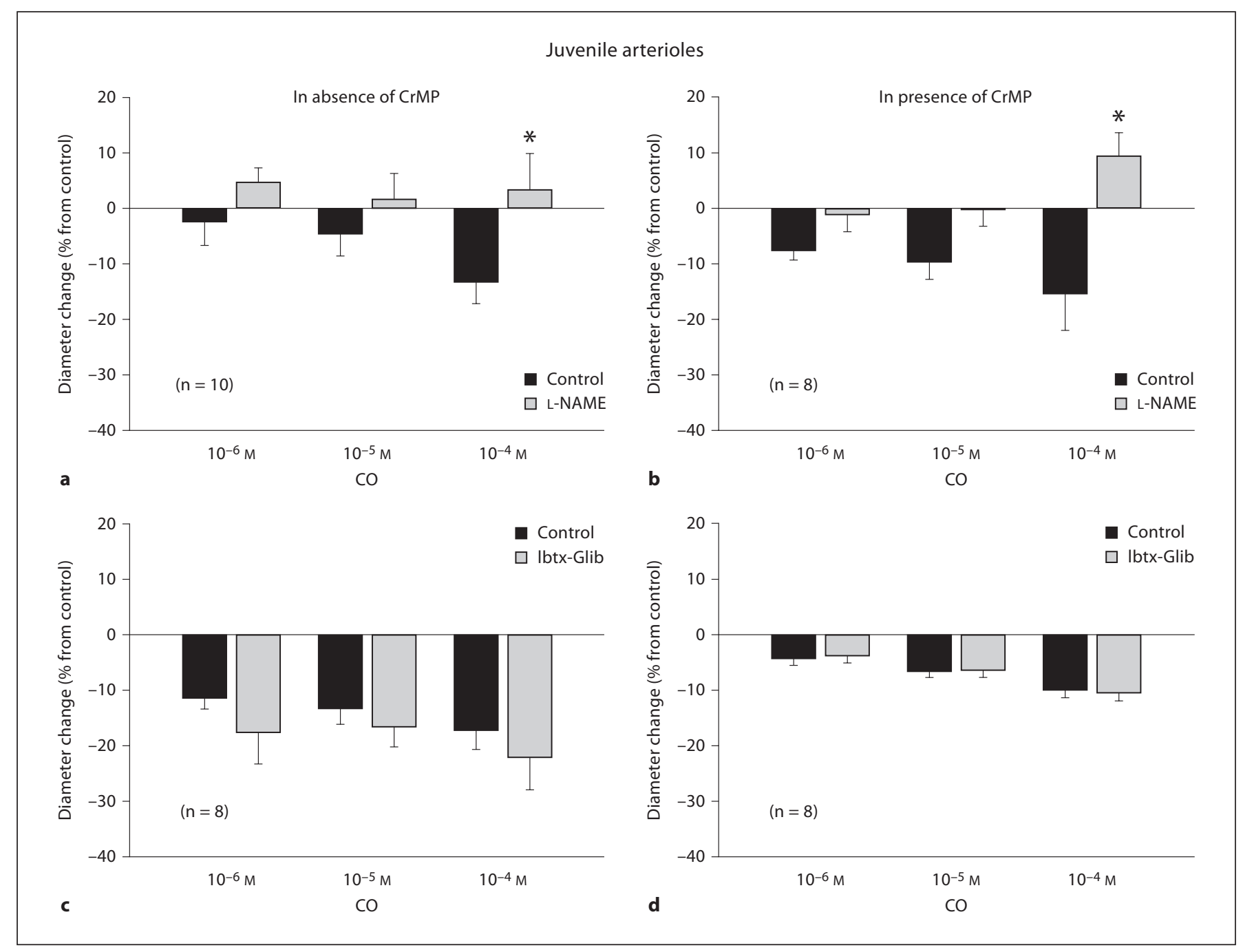

Fig. 2. Responses of arterioles from juvenile rats to exogenous CO before and after NOS inhibition with LNAME alone (a) or in the presence of CrMP (b), and before and after inhibition of $\mathrm{K}_{\mathrm{Ca}}$ and $\mathrm{K}_{\mathrm{ATP}}$ channels with Ibtx + Glib alone (c) or in the presence of CrMP (d). $n=$ Number of vessels. Values are given as means \pm SE. ${ }^{*} \mathrm{p}<0.05$ vs. control.

Although treatment with CrMP did not affect the dilation of juvenile arterioles to $\mathrm{ACh}$, it abolished the dilation of these vessels to simvastatin (fig. 5). However, CrMP treatment reduced the dilation of weanling arterioles to both ACh and simvastatin (fig. 5). Addition of L-NAME after CrMP treatment abolished dilation to ACh and had no further effect on simvastatin responses in juvenile arterioles, and had no further effect on weanling arteriolar responses to ACh or simvastatin (fig. 6). In juvenile arterioles, treatment with Ibtx + Glib following CrMP abolished responses to ACh and had no further effect on responses to simvastatin (fig. 7). In weanling arterioles, treatment with Ibtx + Glib following CrMP had no effect on ACh responses, but reduced the dilation to $10^{-5} \mathrm{M}$ simvastatin (fig. 7).

Western blot analysis of gracilis artery/arteriole homogenates is shown in figure 8 . Vessels from juvenile rats had a significantly lower abundance of HO-1 protein than those from weanling rats. In both groups, the expression of HO-2 was approximately an order of magnitude higher than that of HO-1, but there was no difference in $\mathrm{HO}-2$ protein abundance between weanling and juvenile rats (fig. 8). 


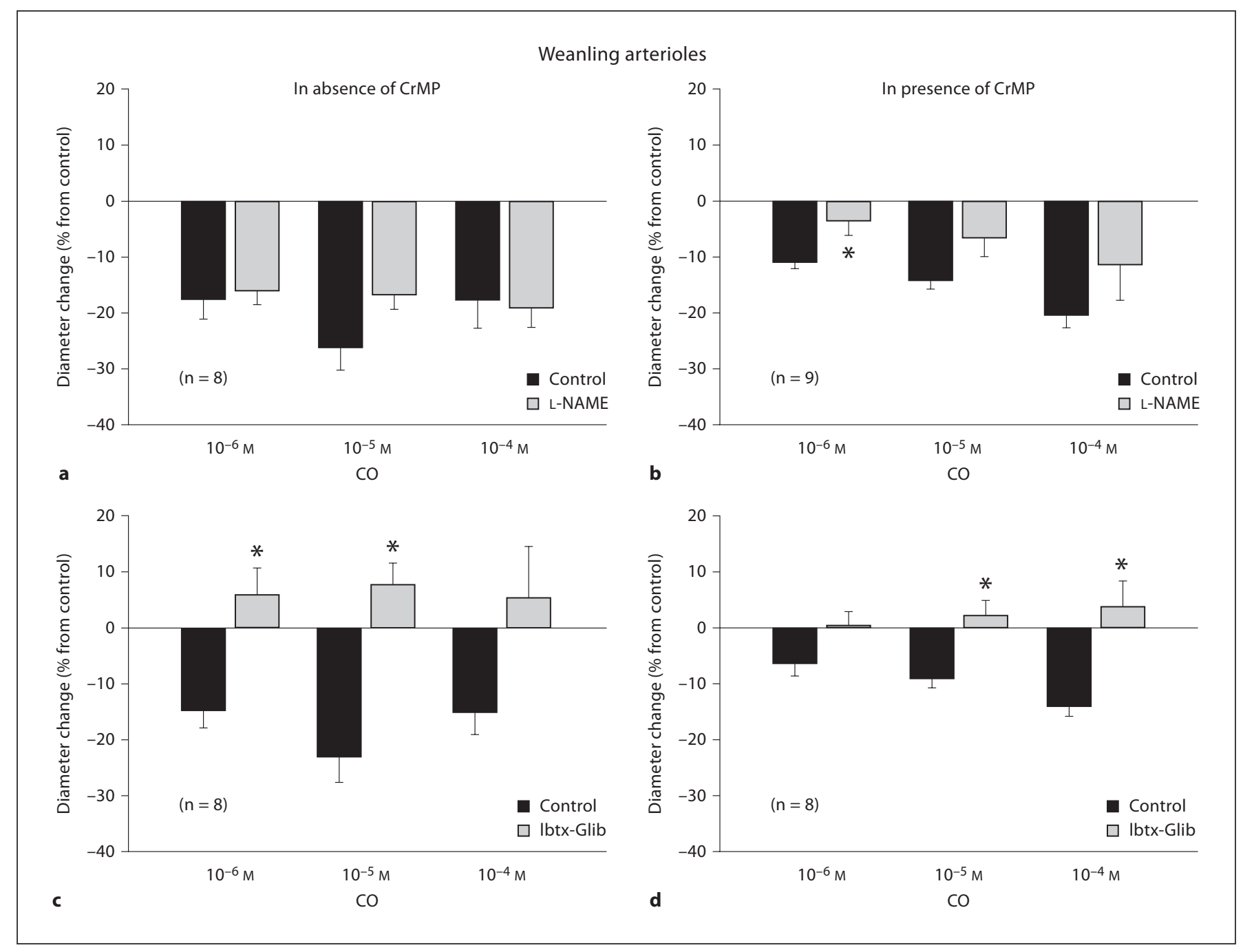

Fig. 3. Responses of arterioles from weanling rats to exogenous CO before and after NOS inhibition with LNAME alone (a) or in the presence of $\operatorname{CrMP}(\mathbf{b})$, and before and after inhibition of $\mathrm{K}_{\mathrm{Ca}}$ and $\mathrm{K}_{\mathrm{ATP}}$ channels with $\mathrm{Ibtx}+\mathrm{Glib}$ alone $(\mathbf{c})$ or in the presence of CrMP (d). Values are given as means $\pm \mathrm{SE}$. ${ }^{*} \mathrm{p}<0.05$ vs. control.

Treatment with CrMP had no effect on the dilation of adult arterioles to $\mathrm{ACh}$, but it abolished the dilation of these vessels to simvastatin (fig. 9). In this regard, the behavior of arterioles from adult rats was virtually identical to that of arterioles from juvenile rats (fig. 5).

\section{Discussion}

Growth-related changes in microvascular endothelial function have been reported by our laboratory and others $[1,4,36]$. In our recent investigations on gracilis muscle arterioles [1, 2], we ruled out NO, prostanoids, cytochrome P-450 metabolites and $\mathrm{H}_{2} \mathrm{O}_{2}$ as possible mediators of endothelium-dependent dilation to various agonists in young (weanling) rats. Since CO has been found to mediate endothelium-dependent dilation of cerebral arterioles in newborn pigs [21], we undertook the current study in part to determine if $\mathrm{CO}$ could be playing an analogous role in the skeletal muscle circulation of weanling rats.

\section{Juvenile Arterioles}

The HO inhibitor CrMP had no effect on the resting diameters of arterioles in any age group (table 2). This 


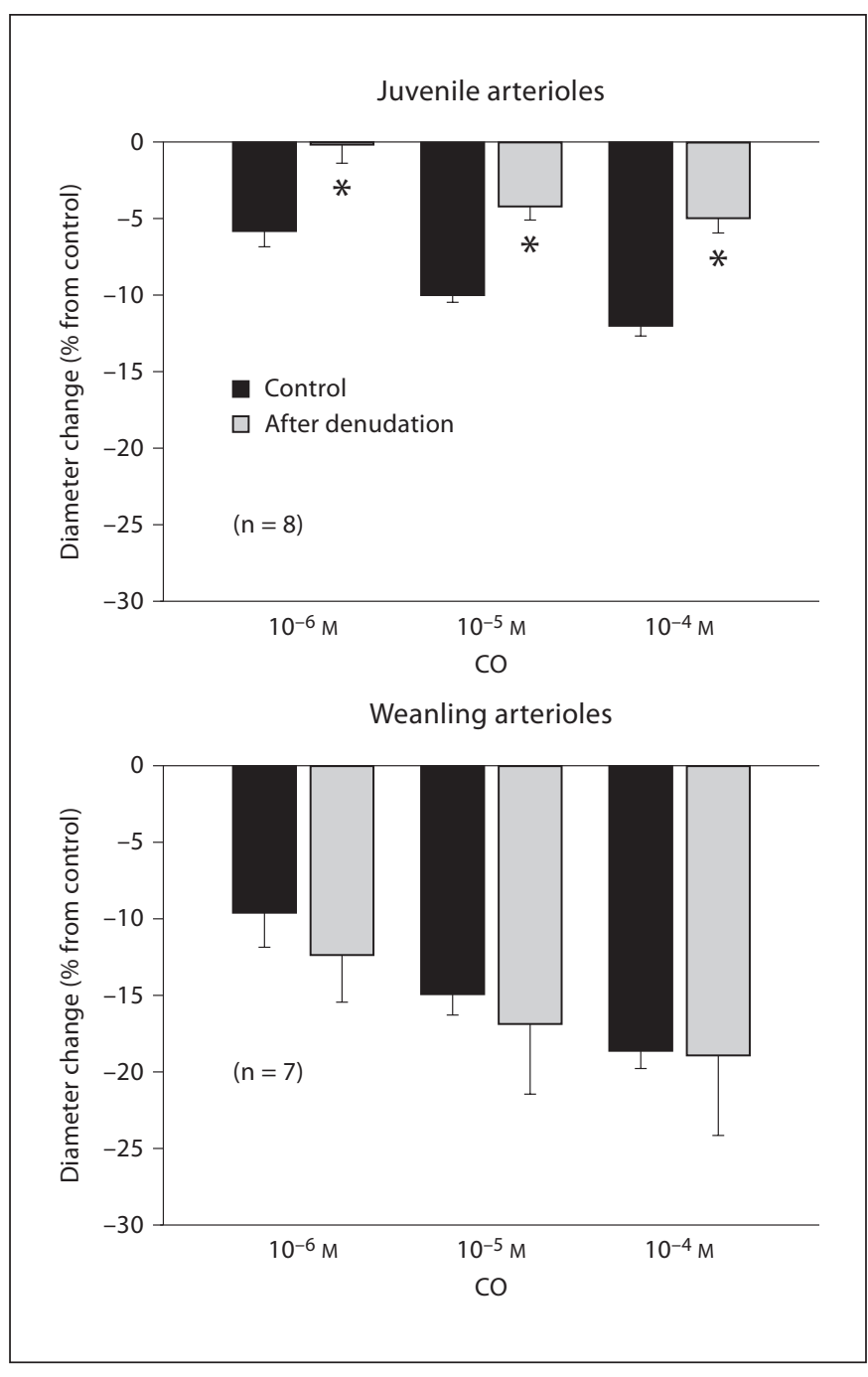

Fig. 4. Effect of endothelial removal on responses of juvenile and weanling arterioles to exogenous $\mathrm{CO}$. Values are given as means \pm SE. ${ }^{*} \mathrm{p}<0.05$ vs. control.

suggests that under the conditions of our study, basal CO release in these vessels, if present, is insufficient to influence resting smooth muscle tone. Similar findings have been reported for larger gracilis muscle arterioles located upstream from those studied here [37] and in various conduit arteries from the rat $[38,39]$. However, CrMP does elicit constriction of gracilis muscle arterioles after these vessels have been pretreated with L-NAME or denuded of their endothelium $[25,37,38]$, which suggests that the effects of basally released NO normally mask the influence of endogenous $\mathrm{CO}$ on resting arteriolar tone. This effect has also been reported in rat renal afferent ar-

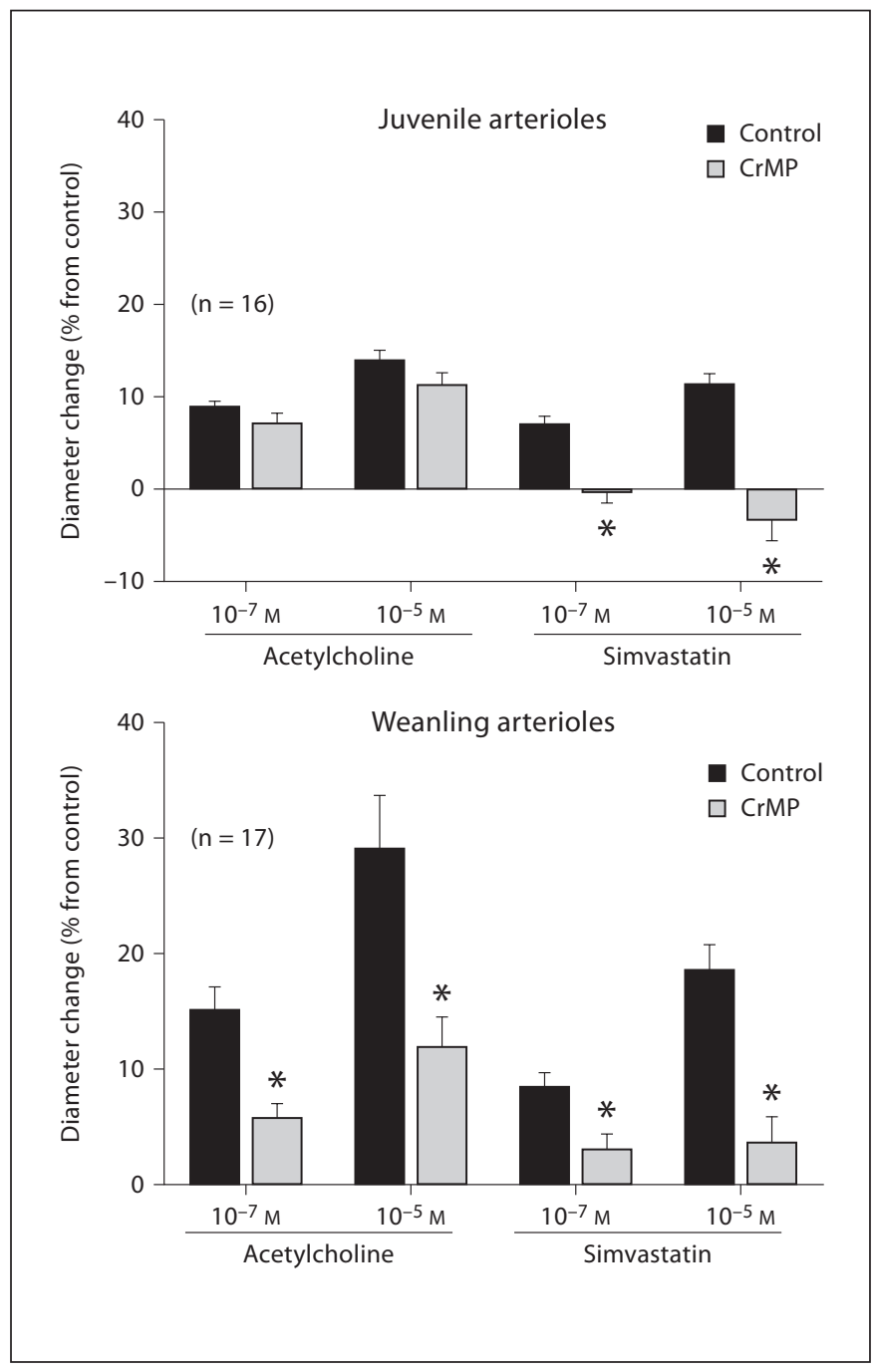

Fig. 5. Effect of CrMP $\left(10^{-5} \mathrm{M}\right)$ on responses of juvenile and weanling arterioles to $\mathrm{ACh}$ and simvastatin. Values are given as means \pm SE. ${ }^{*} \mathrm{p}<0.05$ vs. control.

terioles [40]. Conversely, we found that treatment with L-NAME reduces the diameter of juvenile arterioles under normal conditions, but not if the vessels had been pretreated with CrMP. There have been similar reports for other vessel types [41], and collectively these findings suggest that although a continuous effect of low levels of $\mathrm{NO}$ on resting tone may obscure a similar effect of $\mathrm{CO}$, some level of $\mathrm{HO}$ activity may actually be required for this tonic NO influence to be present in the first place. The exact mechanism of this synergistic effect is not known. CO is not a cofactor or cosubstrate for NOS, but the smooth muscle signaling pathways through which 


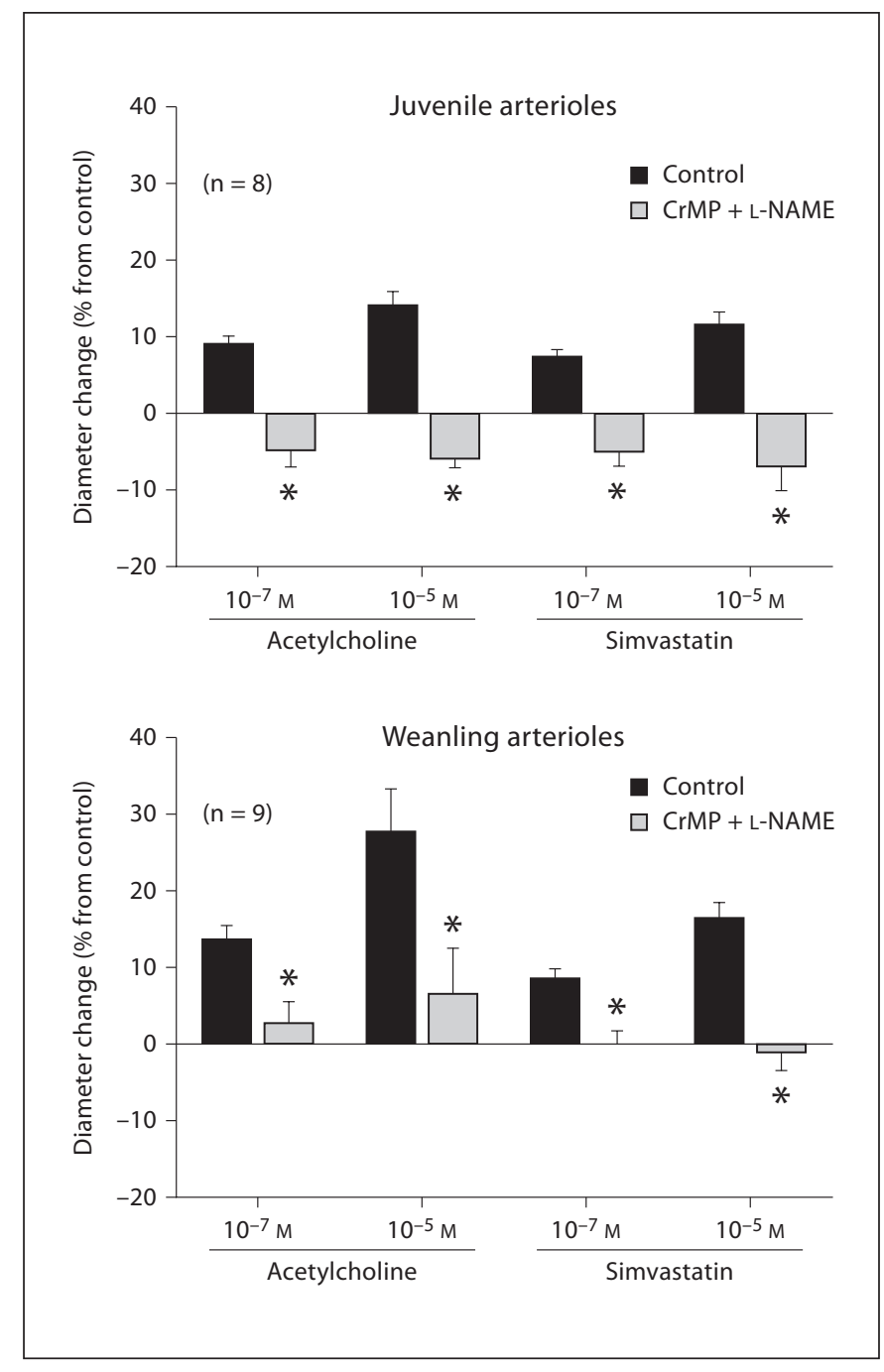

Fig. 6. Responses of arterioles from juvenile and weanling rats to ACh and simvastatin before and after treatment with CrMP and L-NAME. Values are given as means \pm SE. ${ }^{*} \mathrm{p}<0.05$ vs. control.

$\mathrm{CO}$ and $\mathrm{NO}$ act share common elements, including an increase in soluble guanyl cyclase activity and cGMP production [41]. Basally released CO, even at concentrations too low to exert a direct effect on vascular tone, could act to 'prime' the NO signaling pathway in vascular smooth muscle, thereby increasing smooth muscle sensitivity to basally released NO. Low levels of $\mathrm{CO}$ have also been found to induce $\mathrm{NO}$ release from resistance vessels, most likely from a preexisting pool of heme-bound NO [20]. Further studies will be necessary to clarify the complex interaction between $\mathrm{CO}$ and $\mathrm{NO}$ in regulating arteriolar tone.

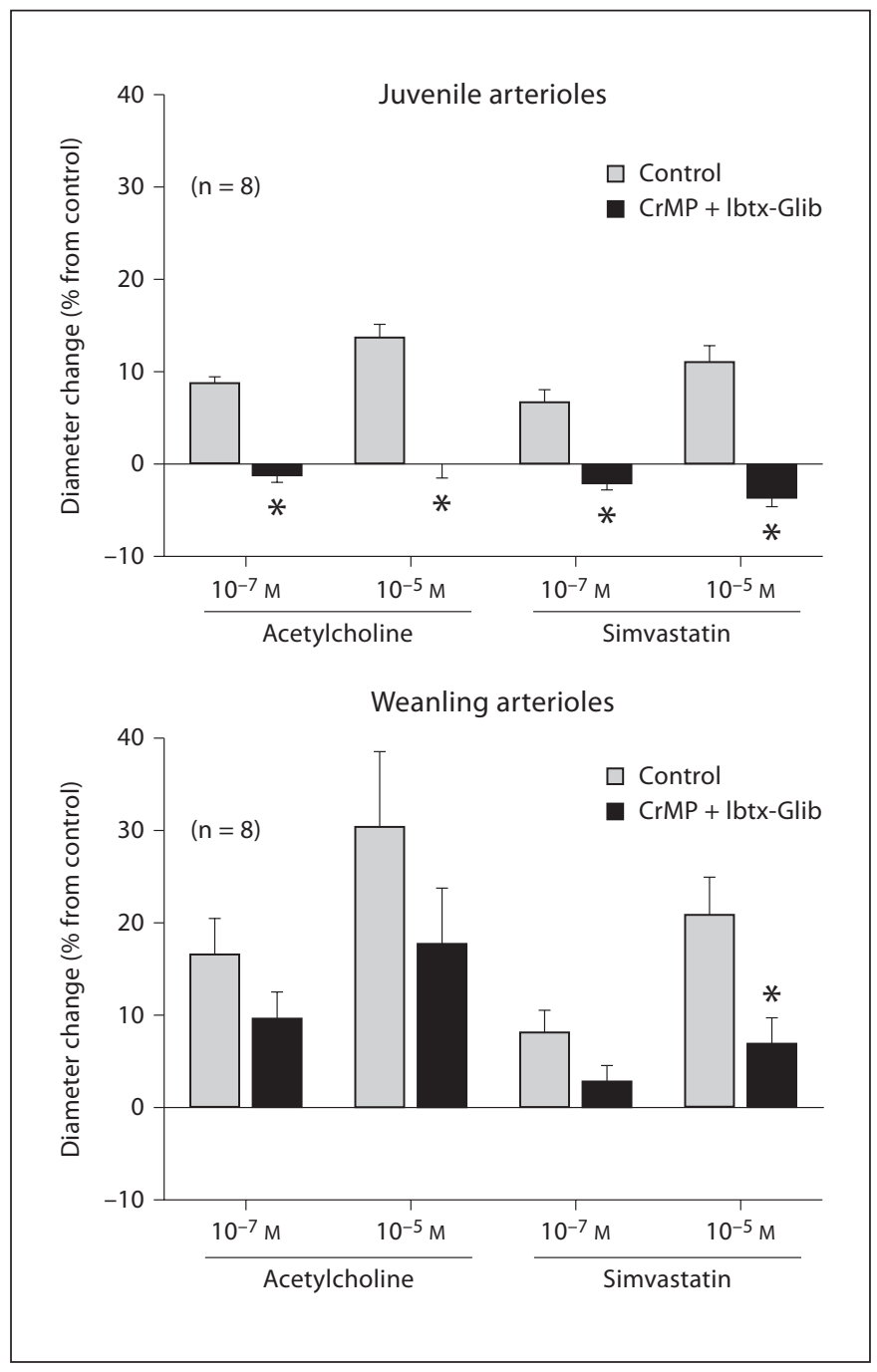

Fig. 7. Responses of arterioles from juvenile and weanling rats to ACh and simvastatin before and after treatment with CrMP and Ibtx-Glib. Values are given as means \pm SE. ${ }^{*} \mathrm{p}<0.05$ vs. control.

The heme precursor $\delta$-ALA increases arteriolar CO production in a dose-dependent manner [42], and our finding that $1 \mu \mathrm{M} \delta$-ALA reduces juvenile arteriole diameters by approximately $25 \%$ (table 2 ) demonstrates that increased endogenous $\mathrm{CO}$ production can increase the resting tone of these vessels. $\delta$-ALA-induced constriction has been reported in larger arterioles from rat gracilis muscle [24], although that effect was more modest (less than $10 \%$ constriction in response to $80 \mu \mathrm{M} \delta$ ALA). The difference in responsiveness to $\delta$-ALA between these 2 studies may reflect a difference in $\mathrm{HO}$ activity or substrate availability between different branch 
Fig. 8. Assessment of HO-1 (a) and HO-2 (b) protein abundance by Western blot in femoral artery/gracilis arteriole segments from both age groups. $\mathrm{W}=$ Weanling vessels; $\mathrm{J}=$ juvenile vessels. Densitometric values for HO-1 and $\mathrm{HO}-2$ are normalized as a fraction of the corresponding value for GAPDH (loading control). Similar findings were observed in three separate experiments. ${ }^{*} \mathrm{p}<0.05$ vs. weanling arterioles.

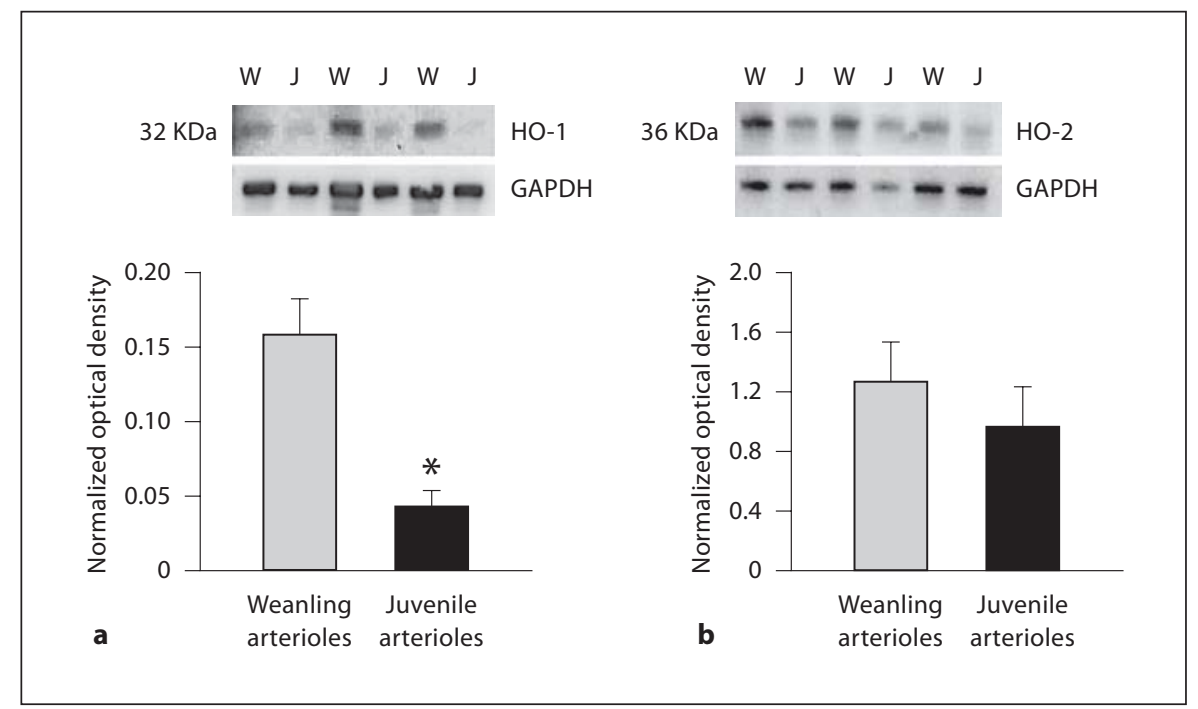

orders in the arteriolar network. In the current study, exogenous $\mathrm{CO}$ at concentrations from $10^{-6}$ to $10^{-4} \mathrm{M}$ also caused arteriolar constriction (fig. 1), which is consistent with the earlier study on larger gracilis muscle arterioles [24].

Relatively high concentrations of $\mathrm{CO}$ induce vascular constriction by inhibiting endothelial NO release [20, 22 $24,41]$, which is consistent with our finding that CO-induced constriction of juvenile arterioles is abolished by L-NAME (fig. 2a, b) and greatly reduced by endothelial denudation (fig. 4). As also shown in figure 2, the highest concentration of $\mathrm{CO}$ elicited a dilation of these arterioles during L-NAME exposure. This is similar to recent findings in renal interlobular arteries [43] and presumably reflects a direct relaxing effect of the exogenous $\mathrm{CO}$ that should predominate once its ability to inhibit endothelial NO release becomes irrelevant. CO-induced vasodilation is mediated by an increase in smooth muscle cGMP levels (see above) and/or activation of $\mathrm{K}_{\mathrm{Ca}}$ channels and membrane hyperpolarization $[21,39,44]$.

Interestingly, a comparison of figures 2 and 4 reveals that endothelial denudation was less effective than L-NAME in reducing arteriolar responses to $10^{-5}$ and $10^{-4} \mathrm{M}$ CO. This may indicate that some of the NO inhibited by $\mathrm{CO}$ is of smooth muscle origin, or it may simply reflect an incomplete removal of the endothelium. However, the latter possibility appears less likely given that our denudation procedure completely abolished arteriolar responses to ACh (see Results). Simultaneous blockade of $\mathrm{K}_{\mathrm{Ca}}$ and $\mathrm{K}_{\mathrm{ATP}}$ channels had no effect on CO-induced constriction of juvenile arterioles (fig. $2 c$, d), indi-

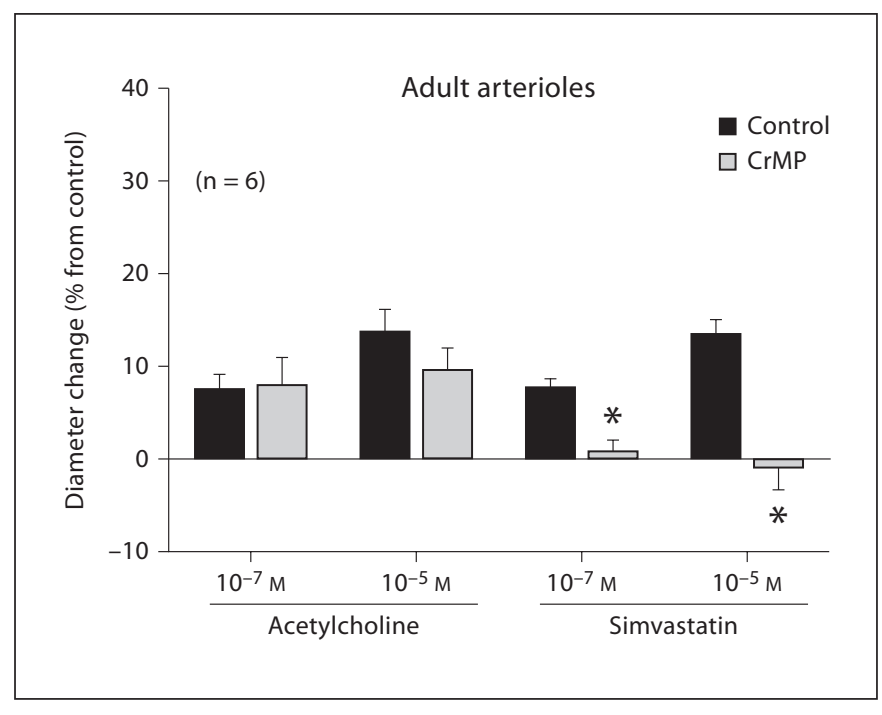

Fig. 9. Effect of CrMP $\left(10^{-5} \mathrm{M}\right)$ on responses of adult arterioles to $\mathrm{ACh}$ and simvastatin. Values are given as means $\pm \mathrm{SE} .{ }^{*} \mathrm{p}<0.05$ vs. control.

cating that a change in $\mathrm{K}^{+}$channel activity normally does not mediate or attenuate the $\mathrm{CO}$-induced constriction of these vessels.

Whereas CrMP had no effect on ACh-induced dilation of these vessels, it completely abolished dilator responses to simvastatin (fig. 5). This suggests that endogenous $\mathrm{CO}$ may mediate some forms of endothelium-dependent dilation, despite our finding that increasing $\mathrm{HO}$ substrate with $\delta$-ALA produced arteriolar constriction. These di- 
vergent results may be due to differences in the concentration of $\mathrm{CO}$ within the arteriolar wall achieved by these two procedures. $\mathrm{CO}$ at lower concentrations (0.01-0.1 $\mu \mathrm{M})$ triggers maximal NO release in rat arterioles, whereas $\mathrm{CO}$ at higher concentrations suppresses $\mathrm{NO}$ release in these vessels [20]. In the rat gracilis muscle arterioles studied here, simvastatin may have triggered a smaller increase in endogenous CO production than that achieved by $\delta$-ALA, leading to lower arteriolar wall $\mathrm{CO}$ levels that could promote dilation. If this is correct, the constriction of these vessels to exogenous $\mathrm{CO}$ in the range of $10^{-6}$ to $10^{-4} \mathrm{M}$ (fig. 1) may reflect a relatively large increase in arteriolar wall CO levels, similar to that triggered by $\delta$-ALA. Unfortunately, we were unable to reliably apply $\mathrm{CO}$ to these vessels at concentrations lower than $10^{-6} \mathrm{M}$. It is difficult to maintain stable CO levels in aqueous solution, and in our hands, dilutions to concentrations below $10^{-6} \mathrm{M}$ introduced an unacceptable degree of uncertainty in the true concentration of $\mathrm{CO}$ in solution.

It is conceivable that the effect of CrMP on juvenile arteriole responses to simvastatin could be due to a reduction in smooth muscle responsiveness to the NO that is released, rather than inhibition of endothelial CO production. However, this seems unlikely, because such a nonspecific effect would also have reduced arteriolar responsiveness to ACh. In addition, control experiments for this study indicate that CrMP has no effect on the responses of juvenile arterioles to the endothelium-independent NO donor SNP. In these experiments, addition of $10^{-7}, 10^{-6}$ and $10^{-5} \mathrm{M}$ SNP to the vessel bath elicited dilations of $5 \pm 1,7 \pm 3$ and $10 \pm 1 \%$ under control conditions versus $4 \pm 1,7 \pm 2$ and $9 \pm 1 \%$ in the presence of CrMP.

A comparison of figures 5 and 9 clearly shows that both the dilations to ACh and simvastatin and the effect (or absence thereof) of CrMP on these responses are identical in the juvenile and 'adult' arterioles we studied. Therefore, age-dependent changes in the contribution of $\mathrm{CO}$ to these responses appear to be complete by the time the animal reaches 6-7 weeks of age. Similarly, previous studies from our laboratory have demonstrated that the ability of the arteriolar endothelium to release NO in response to shear stress increases dramatically from the weanling to the juvenile stage, but does not change further from the juvenile to the adult stage [4]. Taken in aggregate, these findings suggest that with respect to the endothelium-dependent control of arteriolar tone, the adult phenotype appears to be established by $6-7$ weeks of age.
Combined treatment with CrMP + L-NAME abolished the dilation of juvenile arterioles to ACh as well as simvastatin (fig. 6). We previously demonstrated that these responses are entirely endothelium-dependent, and that L-NAME treatment alone reduces juvenile arteriole responses to ACh and simvastatin by approximately 90 and $60 \%$, respectively [1]. Our current findings, taken together with these previous findings, suggest that although simvastatin releases endothelium-derived $\mathrm{CO}$ in addition to NO, ACh does not. Combined $\mathrm{K}_{\mathrm{ATP}}$ and $\mathrm{K}_{\mathrm{Ca}}$ channel inhibition abolished ACh-induced dilations in the presence of CrMP (fig. 7). We previously demonstrated that inhibition of both channel types in juvenile arterioles reduces ACh responses by $60-70 \%$ [1]. Our current finding that the additional presence of CrMP leads to a complete abolition of $\mathrm{ACh}$ responses is surprising, since CrMP treatment alone had no effect on ACh-induced dilation (fig. 5). This finding may be attributable to some nonspecific effect of CrMP in these experiments.

\section{Weanling Arterioles}

As with juvenile arterioles, CrMP had no effect on the resting diameter of weanling arterioles (table 2), suggesting that basally produced $\mathrm{CO}$ also does not influence the resting tone of arterioles from younger rats. However, unlike juvenile arterioles, the diameter of weanling arterioles was also unaffected by $\delta$-ALA, indicating that even when the substrate for $\mathrm{HO}$ is increased, $\mathrm{CO}$ is still not produced in quantities large enough to influence arteriolar tone at this earlier stage of growth.

Leffler et al. [21] have reported that exogenous CO dilates cerebral arterioles of newborn pigs in vivo. In contrast, exogenous $\mathrm{CO}$ constricted the weanling arterioles we studied, in some cases even more than that seen with juvenile arterioles (fig. 1). Although this could reflect normal differences between species or vascular beds, it is also possible, as discussed above, that differences in $\mathrm{CO}$ concentration reached within the arteriolar wall could explain these divergent observations. Whereas the COinduced dilations in newborn pigs occurred at superfusate concentrations ranging from $10^{-11}$ to $10^{-7} \mathrm{M}$, with maximal dilation at $10^{-9} \mathrm{M}$ [42], we applied $\mathrm{CO}$ at bath concentrations between $10^{-6}$ and $10^{-4} \mathrm{M}$.

Although exogenous $\mathrm{CO}$ did not dilate our weanling arterioles, we found reduced dilations to ACh and simvastatin in the presence of CrMP (fig. 5), suggesting that a portion of this endothelium-dependent dilation is due to endogenous $\mathrm{CO}$ release. In these experiments, endogenously produced $\mathrm{CO}$ in the arteriolar wall may have been in the concentration range reached by Leffler et al. 
[21], which could produce dilation, rather than the higher concentrations we applied exogenously, which produced constriction. In contrast to juvenile arterioles, LNAME did not affect CO-induced constriction of weanling arterioles (fig. 3a, b), suggesting that a decrease in NO production does not mediate these responses. Although L-NAME did reduce the resting diameter of the weanling arterioles, this did not happen after CrMP treatment, which is similar to our findings in juvenile arterioles and suggests that some level of $\mathrm{HO}$ activity is also required for basal NO to modulate resting arteriolar tone at this earlier stage of growth.

In contrast to our findings in the juvenile arterioles, $\mathrm{K}^{+}$channel inhibitors abolished the constrictor effect of $\mathrm{CO}$ in weanling arterioles (fig. $3 \mathrm{c}, \mathrm{d}$ ). This finding that some initial level of $\mathrm{K}^{+}$channel activity is required for this response suggests that $\mathrm{CO}$ may constrict weanling arterioles by inhibiting $\mathrm{K}^{+}$channel activity in vascular smooth muscle. Endothelial denudation had no effect on this response (fig. 4), which is consistent with a decrease in smooth muscle $\mathrm{K}^{+}$channel activity being the predominant mechanism of CO-induced constriction. However, this contrasts with other reports that $\mathrm{CO}$ increases the activity of smooth muscle $\mathrm{K}_{\mathrm{Ca}}$ channels to induce dilation of gracilis muscle arterioles and other vessels from the rat $[14,44]$. These previous studies involved rats that were older than the weanlings studied here, with ages corresponding to our juvenile or adult groups. This raises the possibility that in the rat, postnatal growth could be accompanied by a change in the overall effect of $\mathrm{CO}$ on vascular $\mathrm{K}^{+}$channels. Our finding that $\mathrm{K}^{+}$channel activity is not required for $\mathrm{CO}$-induced constriction of juvenile arterioles (see above) is consistent with such a change, but further studies are required to critically test this hypothesis. It is also important to point out that there are vascular beds in which such a change clearly does not occur. For example, exogenous $\mathrm{CO}$ triggers a $\mathrm{K}^{+}$channel-dependent dilation of cerebral arterioles in pigs at only 3 days of age [21], and does not elicit a constriction of these vessels at any age [45].
HO-1 and HO-2 are present in both the vascular smooth muscle and endothelium of gracilis muscle arterioles [37], and we found no difference between weanling and juvenile rats in vascular $\mathrm{HO}-2$ protein abundance (fig. 8). HO-2 is the constitutive isoform of the protein and responsible for acute changes in CO production [15]. This suggests that changes in $\mathrm{HO}$ activity, rather than its expression, underlie the differences we found between weanling and juvenile arterioles. In contrast, we found a relatively large age-related reduction in vascular $\mathrm{HO}-1$ abundance. The reason for this difference between age groups is not clear, but one possibility is that the lower HO-1 expression in juveniles reflects an age-related difference in the shear stresses to which these vessels are normally exposed. Shear stress is an effective inducer of HO-1 expression [14], and we have previously documented that hemodynamic shear stress in rat skeletal muscle arterioles undergoes a large reduction between the weanling and juvenile stages studied here [4]. Further studies would be required to critically test this hypothesis.

In summary, the role of $\mathrm{CO}$ in regulating arteriolar tone appears to change during juvenile growth. Exogenous $\mathrm{CO}$ at $10^{-6}$ to $10^{-4} \mathrm{M}$ produces arteriolar constriction mediated by $\mathrm{K}^{+}$channel inhibition and smooth muscle depolarization in weanling vessels, but by NO inhibition in juvenile vessels. Endogenous $\mathrm{CO}$ contributes to the endothelium-dependent dilation of arterioles from both age groups, but this role for CO may be more widespread in weanling arterioles. Such differences underscore the importance of further studies to define the effect of postnatal growth on microvascular function to more fully understand the mechanisms of blood flow regulation during this critical period.

\section{Acknowledgements}

This work was funded by the American Heart Association (0330194N to J.C.F. and 0150199 N to M.A.B.) and the National Institutes of Health (DK 64668 to J.C.F. and HL 44012 to M.A.B.).
References

Carbon Monoxide and Arteriolar Tone
1 Balch Samora J, Frisbee J, Boegehold M: Growth-dependent changes in endothelial factors regulating arteriolar tone. Am J Physiol 2007;292:H207-H214.

-2 Balch Samora J, Frisbee JC, Boegehold MA Hydrogen peroxide emerges as a regulator of tone in skeletal muscle arterioles during juvenile growth. Microcirculation 2008; 15 : 151-161.
3 Linderman JR, Boegehold MA: Arteriolar network growth in rat striated muscle during juvenile maturation. Int J Microcirc Clin Exp 1996;16:232-239.

4 Linderman JR, Boegehold MA: Growth-related changes in the influence of nitric oxide on arteriolar tone. Am J Physiol 1999;277: H1570-H1578. 
5 Fiumana E, Parfenova H, Jaggar JH, Leffler CW: Carbon monoxide mediates vasodilator effects of glutamate in isolated pressurized cerebral arterioles of newborn pigs. Am J Physiol 2003;284:H1073-H1079.

6 Gonzales RJ, Walker BR: Role of CO in attenuated vasoconstrictor reactivity of mesenteric resistance arteries after chronic hypoxia. Am J Physiol 2002;282:H30-H37.

$\checkmark 7$ Kanu A, Whitfield J, Leffler CW: Carbon monoxide contributes to hypotension-induced cerebrovascular vasodilation in piglets. Am J Physiol 2006;291:H2409-H2414.

$\checkmark 8$ Maines MD: The heme oxygenase system: a regulator of second messenger gases. Annu Rev Pharmacol Toxicol 1997;37:517-554.

-9 Marks GS, McLaughlin BE, Vreman HJ, Stevenson DK, Nakatsu K, Brien JF, Pang SC: Heme oxygenase activity and immunohistochemical localization in bovine pulmonary artery and vein. J Cardiovasc Pharmacol 1997;30:1-6.

-10 Parfenova H, Neff RA 3rd, Alonso JS, Shlopov BV, Jamal CN, Sarkisova SA, Leffler CW: Cerebral vascular endothelial heme oxygenase: expression, localization, and activation by glutamate. Am J Physiol 2001;281:C1954C1963.

$\checkmark 11$ Christodoulides N, Durante W, Kroll MH, Schafer AI: Vascular smooth muscle cell heme oxygenases generate guanylyl cyclasestimulatory carbon monoxide. Circulation 1995;91:2306-2309.

-12 Yet SF, Pellacani A, Patterson C, Tan L, Folta SC, Foster L, Lee WS, Hsieh CM, Perrella MA: Induction of heme oxygenase-1 expression in vascular smooth muscle cells: a link to endotoxic shock. J Biol Chem 1997;272: 4295-4301.

-13 Ewing JF, Raju VS, Maines MD: Induction of heart heme oxygenase-1 (HSP32) by hyperthermia: possible role in stress-mediated elevation of cyclic $3^{\prime}: 5^{\prime}$-guanosine monophosphate. J Pharmacol Exp Ther 1994;271: 408-414.

- 14 Warabi E, Wada Y, Kajiwara H, Kobayashi M, Koshiba N, Hisada T, Shibata M, Ando J, Tsuchiya M, Kodama T, Noguchi N: Effect on endothelial cell gene expression of shear stress, oxygen concentration, and low-density lipoprotein as studied by a novel flow cell culture system. Free Radic Biol Med 2004;37: 682-694.

-15 Ding Y, McCoubrey WK Jr, Maines MD: Interaction of heme oxygenase-2 with nitric oxide donors. Is the oxygenase an intracellular 'sink' for NO? Eur J Biochem 1999;264: 854-861.

16 Johnson RA, Kozma F, Colombari E: Carbon monoxide: from toxin to endogenous modulator of cardiovascular functions. Braz J Med Biol Res 1999;32:1-14.

$\checkmark 17$ Furchgott RF, Jothianandan D: Endothelium-dependent and -independent vasodilation involving cyclic GMP: relaxation induced by nitric oxide, carbon monoxide and light. Blood Vessels 1991;28:52-61.
18 Lin H, McGrath JJ: Vasodilating effects of carbon monoxide. Drug Chem Toxicol 1988; 11:371-385.

19 Steinhorn RH, Morin FC 3rd, Russell JA: The adventitia may be a barrier specific to nitric oxide in rabbit pulmonary artery. J Clin Invest 1994;94:1883-1888.

20 Thorup C, Jones CL, Gross SS, Moore LC, Goligorsky MS: Carbon monoxide induces vasodilation and nitric oxide release but suppresses endothelial NOS. Am J Physiol 1999; 277:F882-F889.

-21 Leffler CW, Nasjletti A, Yu C, Johnson RA, Fedinec AL, Walker N: Carbon monoxide and cerebral microvascular tone in newborn pigs. Am J Physiol 1999;276:H1641-H1646.

22 Pufahl RA, Marletta MA: Oxidation of $\mathrm{N}^{\mathrm{G}}$ hydroxy-L-arginine by nitric oxide synthase: evidence for the involvement of the heme in catalysis. Biochem Biophys Res Commun 1993;193:963-970.

23 White KA, Marletta MA: Nitric oxide synthase is a cytochrome P-450 type hemoprotein. Biochemistry 1992;31:6627-6631.

24 Johnson FK, Johnson RA: Carbon monoxide promotes endothelium-dependent constriction of isolated gracilis muscle arterioles. Am J Physiol 2003;285:R536-R541.

25 Kozma F, Johnson RA, Nasjletti A: Role of carbon monoxide in heme-induced vasodilation. Eur J Pharmacol 1997;323:R1-R2.

-26 Fredricks KT, Liu Y, Lombard JH: Response of extraparenchymal resistance arteries of rat skeletal muscle to reduced $\mathrm{PO}_{2}$. Am J Physiol 1994;267:H706-H715.

27 DeLano FA, Schmid-Schonbein GW, Skalak TC, Zweifach BW: Penetration of the systemic blood pressure into the microvasculature of rat skeletal muscle. Microvasc Res 1991;41: 92-110.

28 Andresen JJ, Shafi NI, Durante W, Bryan RM Jr: Effects of carbon monoxide and heme oxygenase inhibitors in cerebral vessels of rats and mice. Am J Physiol 2006;291:H223H230.

29 Vreman HJ, Ekstrand BC, Stevenson DK: Selection of metalloporphyrin heme oxygenase inhibitors based on potency and photoreactivity. Pediatr Res 1993;33:195-200.

-30 Appleton SD, Chretien ML, McLaughlin BE, Vreman HJ, Stevenson DK, Brien JF, Nakatsu K, Maurice DH, Marks GS: Selective inhibition of heme oxygenase, without inhibition of nitric oxide synthase or soluble guanyly cyclase, by metalloporphyrins at low concentrations. Drug Metab Dispos 1999;27: 1214-1219

-31 Frisbee JC, Roman RJ, Murali Krishna U, Falck JR, Lombard JH: Altered mechanisms underlying hypoxic dilation of skeletal muscle resistance arteries of hypertensive versus normotensive Dahl rats. Microcirculation 2001;8:115-127.

-32 Nelson MT, Quayle JM: Physiological roles and properties of potassium channels in arterial smooth muscle. Am J Physiol 1995;268: C799-C822.
33 Lombard JH, Liu Y, Fredricks KT, Bizub DM, Roman RJ, Rusch NJ: Electrical and mechanical responses of rat middle cerebral arteries to reduced $\mathrm{PO}_{2}$ and prostacyclin. Am J Physiol 1999;276:H509-H516.

-34 Standen NB, Quayle JM, Davies NW, Brayden JE, Huang Y, Nelson MT: Hyperpolarizing vasodilators activate ATP-sensitive $\mathrm{K}^{+}$channels in arterial smooth muscle. Science 1989; 245:177-180.

35 Uluoglu C, Zengil H: Comparison of different de-endothelization procedures in the isolated rat thoracic aorta: a short communication. Res Commun Mol Pathol Pharmacol 2003;113-114:289-297.

36 Willis AP, Leffler CW: Endothelial NO and prostanoid involvement in newborn and juvenile pig pial arteriolar vasomotor responses. Am J Physiol 2001;281:H2366-H2377.

37 Johnson FK, Teran FJ, Prieto-Carrasquero M, Johnson RA: Vascular effects of a heme oxygenase inhibitor are enhanced in the absence of nitric oxide. Am J Hypertens 2002; 15:1074-1080.

38 Kozma F, Johnson RA, Zhang F, Yu C, Tong $\mathrm{X}$, Nasjletti A: Contribution of endogenous carbon monoxide to regulation of diameter in resistance vessels. Am J Physiol 1999;276: R1087-R1094.

39 Wang R, Wang Z, Wu L: Carbon monoxideinduced vasorelaxation and the underlying mechanisms. Br J Pharmacol 1997;121:927934.

40 Botros FT, Navar LG: Interaction between endogenously produced carbon monoxide and nitric oxide in regulation of renal afferent arterioles. Am J Physiol 2006;291:H2772H2778.

41 Foresti R, Green CJ, Motterlini R: Nitric oxide and the heme oxygenase/carbon monoxide system: cooperation in the control of vascular function; in Wang $\mathrm{R}$ (ed): Carbon Monoxide and Cardiovascular Functions. Boca Raton, CRC Press, 2002, pp 111-124.

-42 Leffler CW, Balabanova L, Sullivan CD, Wang X, Fedinec AL, Parfenova H: Regulation of CO production in cerebral microvessels of newborn pigs. Am J Physiol 2003;285: H292-H297.

43 Rodriguez F, Zhang F, Dinocca S, Nasjletti A: Nitric oxide synthesis influences the renal vascular response to heme oxygenase inhibition. Am J Physiol 2003;284:F1255-F1262.

44 Zhang F, Kaide J, Wei Y, Jiang H, Yu C, Balazy M, Abraham NG, Wang W, Nasjletti A: Carbon monoxide produced by isolated arterioles attenuates pressure-induced vasoconstriction. Am J Physiol 2001;281:H350H358.

45 Holt DC, Fedinec AL, Vaughn AN, Leffler CW: Age and species dependence of pial arteriolar responses to topical carbon monoxide in vivo. Exp Biol Med 2007;232:14651469. 